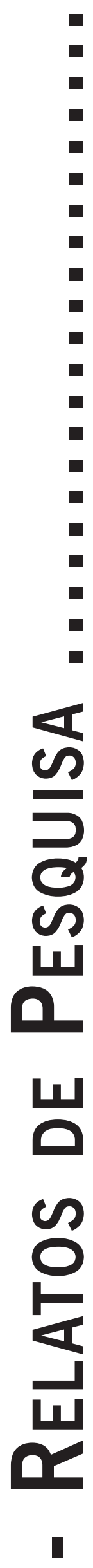




\title{
A PSICOLOGIA HUMANISTA NA REVISTA "PSICOLOGIA ATUAL" DE 1977-1986: UM ENSAIO HERMENÊUTICO
}

\author{
Humanistic Psychology in "Psicologia Atual" Journal from 1977-1986: \\ A Hermeneutic Approach \\ La Psicología Humanista en la Revista "Psicologia Atual" del 1977-1986: \\ Un Ensayo Hermenêutico
}

FELIPE Sacomano

NiLTON JÚlio DE FARIA

Yuri AlEXANDRE FERRETE

\begin{abstract}
Resumo: As décadas de 1970 e 1980 foram cenários para grandes transformações sociais no Brasil. A psicologia, como profissão, inaugurou a década de 1970 como uma novidade àqueles que buscavam alternativas aos valores apregoados pela ditadura militar, mas, ao mesmo tempo, servia para a manutenção deles. A criação de cursos de psicologia e a aceitação social desta ciência e profissão possibilitaram o surgimento de veículos de comunicação que facilitassem a difusão de conhecimentos e de fazeres psicológicos. Dentre eles, destaca-se a revista Psicologia Atual, que foi publicada em 1977 e perdurou até 1986, pelo Grupo Editorial Spagat. A presente pesquisa teve por objetivos identificar diferentes conteúdos associados à Psicologia Humanista publicados na revista, identificar os seus proponentes e depreender significados dos conteúdos publicados. Os conteúdos identificados foram categorizados em artigos, reportagens e entrevistas, e analisados por meio do método hermenêutico proposto por Hans-Georg Gadamer. Os resultados indicaram a prevalência do Psicodrama, seguido pela Gestalt-Terapia e pela Abordagem Centrada na Pessoa, nos artigos e entrevistas. As reportagens noticiavam as visitas de eminentes psicólogos estrangeiros aos Brasil. Concluiu-se que a Psicologia Humanista apresentava uma preocupação com temas sociais significativos à época, tais como família, interioridade, sexualidade e trabalho, contribuindo para uma visão subjetivista com a qual, muitas vezes, ela é relacionada.
\end{abstract}

Palavras-chave: Psicologia Humanista; História da Psicologia; Abordagem Centrada na Pessoa; Gestalt-Terapia; Psicodrama.

Abstract: The 1970 and 1980 decades were times of great social transformations in Brazil. Psychology, as a profession, appeared in the 70's as a useful novelty for those who seeked alternatives to the principles proclaimed by the military dictatorship, and at the same time serving as a way to maintain such divergent values. The creation of psychology courses, and the social acceptance of this science and it's profession allowed for the development of medias that eased the propagation of knowledge and of psychological affairs. Amongst these medias, the journal Psicologia Atual stands out, it was first published in 1977 and lasted until 1986, brought by the Grupo Editorial Spagat. This research had in it's purpose to identify diferent contents associated with Humanistic Psychology published in the journal, identifying their conceivers and infer meanings which were assigned to these. The identified contents were categorized in articles, reports and interviews, whose contents were analised by the hermeneutic method proposed by Hans-Georg Gadamer. The results indicated the prevalence of Psychodrama, followed by Gestalt Therapy and Person-Centred Approach, in the articles and interviews categories. The reports announced notable foreign psichologist's visits to Brazil. It is concluded that Humanistic Psychology displayed a concern with social issues relevant to the time period, such as family, inwardness, sexuality and work, contributing to a subjectivist vision to which, many times, it is associated.

Keywords: Humanistic Pyschology; History of Psychology; Person-Centred Approach; Gestalt-Therapy; Psychodrama.

Resumen: Las décadas del 1970 y 1980 fueron escenarios para grandes transformaciones sociales en Brasil. La psicología, como profesión, tuvo inicio en la década del 1970 como una novedad para aquellos que buscaban alternativas a los valores promocionados por la dictadura militar, pero, al mismo tempo, servia para la manutención de los mismos. La creación de los cursos de psicologia y la aceptación social de esta ciencia y profesión, posibilitaron la creación de vehículos de comunicación que facilitaron la difusión de conocimientos y hechos psicológicos. Dentre ellos, destaca-se la revista Psicologia Atual, que fue publicada en el 1977 y duró hasta el 1986, por el Grupo Editorial Spagat. La presente pesquisa tiene como objetivos identificar diferentes contenidos asociados a la Psicologia Humanista publicados en la revista, identificar sus proponentes y obtener los significados de los contenidos publicados. Los contenidos identificados fueron categorizados en artigos, reportajes y entrevitas, que luego fueron analisados, através del método hermeneutico propuesto por Hans-Georg Gadamer. Los resultados indicaron el predomínio del Psicodrama, seguido por la Gestalt-Terapia y el Enfoque Centrado en la Persona, em los artigos y entrevistas. Los reportajes reportaban las visitas de nuevos psicólogos extranjeros a Brasil. Concluye-se que la psicologia Humanista apresentaba uma preocupación com temas sociales significativos de la época, como la família, el ser interior, sexualidade y trabajo, contribuyendo para una visión subjetiva con la qual, muhas veces, ella es relacionada.

Palavras-clave: Psicología Humanista; Historia de la Psicología; Enfoque Centrado en la Persona; Gestalt-Terapia; Psicodrama. 


\section{Introdução}

O presente artigo tem por objetivo compreender o modo como a Psicologia Humanista foi veiculada pela Revista Psicologia Atual que circulou em território nacional no período de 1977 a 1986. Considerando que o ensaio hermenêutico de um texto histórico requer diversas atenções singulares para que o mesmo esteja coerente com a época em que esse texto foi produzido, faz-se importante destacarmos alguns fatores históricos presentes naquele contexto. Para isso, privilegiou-se como única fonte o livro de Cecília Coimbra, Guardiões da Ordem (1995), como referência para buscar o momento histórico contemporâneo a revista.

A dimensão política que antecedeu a publicação da revista foi significativa para a construção de um modo de vida que caracterizou a década de 1970: diante da necessidade da quebra da barreira gerada pelo governo populista de João Goulart, que impedia a expansão monopolista do capital estrangeiro, os militares tomaram posse do país em 1964. O cerceamento à liberdade de expressão advindo de tal fato, sugere que a construção da subjetividade do brasileiro tenha começado a tomar novo caminho. Exemplo disso é que qualquer movimento, individual ou coletivo, contrário à ordem dada, era demarcado como traição à pátria, fazendo de qualquer cidadão ligado a esse movimento um indivíduo a ser castigado por perturbar a paz. Criou-se, assim, o "inimigo da nação", fortalecido pelas marchas das famílias, aliadas à elite da igreja, pela luta contra a peste que poderia interferir no desenvolvimento saudável do novo brasileiro (Coimbra, 1995).

Nas universidades constitui-se, pouco a pouco, a nova classe média branca, que acreditava ser diferente da massa popular em virtude de seu conhecimento intelectual. As mulheres passaram a buscar sua autonomia não mais por meio do casamento, mas sim pela sua inserção no mundo do trabalho, pela busca de direitos equitativos aos dos homens, questionando até mesmo a monogamia (Coimbra, 1995).

Cecília Coimbra (1995) destaca, ainda, que a força militar que comandava o país conseguiu frear a cultura de esquerda, hegemônica até então, trabalhando assim o ideário alienante nacionalista-populista. O poderio dos generais foi consolidado com a vitória dos militares no Chile e no Uruguai, no ano de 1973, assim como em nossa vizinha Argentina, em 76. Foram sangrentas e impiedosas ditaduras, baseadas na repressão, na violência e na imposição militar para manter o desenvolvimento econômico e a segurança nacional.

No Brasil, o órgão responsável por esse controle foi criado três meses após a posse e denominado Serviço Nacional de Informações (SNI). Esse setor foi o responsável por aproximar o Brasil das elites militares do mundo, alcançando ser a quarta força em todo o planeta. As forças unificadas antiguerrilhas e os grupos paramilitares, subsidiados pelo Estado junto às grandes empresas, auxiliaram nesse poder de repressão e opressão (Coimbra, 1995).
A classe média aderiu à ditadura fortalecendo o consumismo, pois o "milagre econômico" possibilitava o "enriquecimento" dos mais necessitados, facilitando o acesso às mercadorias tão aclamadas nas propagandas. O Brasil havia se tornado a ilha da tranquilidade, onde as multinacionais encontravam o "pote de ouro". O ufanismo estava solto, a elite branca esbanjando riqueza, enquanto a classe média pegava as sobras do milagre, acreditando estar crescendo. (Saviani, 2008). As tecnologias de comunicação passaram a entrar de vez na vida do brasileiro, como o monopólio da TV Globo, que teve seu apogeu nos anos 1980 e 1990. Com a forte censura na rua, restava ao brasileiro assistir à televisão e ele, agora "rico", passa a comprar e se divertir mais. Nesse tempo, no entanto, as pequenas emissoras lutavam para tentar propagar suas ideias, fugindo da neutralidade dos grandes jornais, colocando-se em contraposição ao governo. (Coimbra, 1995)

No povo, o fortalecimento da ditadura esteve diretamente ligado à redução do indivíduo ao intimismo, fazendo o brasileiro observar apenas a si próprio, para que não tivesse tempo e interesse em compreender as questões sociais. Ideais de estruturas familiares foram pregados por toda a classe média e média alta, assim como fortaleceu-se, também, a imagem de um trabalhador ideal. Era dever do brasileiro-trabalhador ser capaz de sustentar sua família e de enriquecer-se junto ao país e, ao mesmo tempo, conter a rebeldia de seu filho para que não se envolvesse no movimento "hippie", por exemplo; caso contrário, a sua seria sinônimo de uma família desonrosa. Qualquer família que sofresse com o desaparecimento de um filho, que tivesse partido a um movimento militante, ou falecido por substâncias químicas, carregava a culpa pelo fato (Coimbra, 1995).

O privado, a família, tornaram-se refúgio contra os terrores da sociedade: negava-se o que acontecia fora e voltava-se para o que acontece dentro do indivíduo. Pregava-se o ideário de uma sociedade de indivíduos iguais, e se o mundo nos frustrasse demais, deveríamos ignorá-lo e viver a própria vida. A valorização do trabalho ou da política era considerada uma atitude muito inferior, dados os encantos da intimidade familiar amorosa. Havia uma concepção de que o indivíduo possuía certa quantidade de energia limitada e que esta não deveria ser gasta de maneira incorreta, com a possibilidade de ela voltar-se contra si próprio. O cotidiano politizado poderia ter como contrapartida o desafeto da vida privada (Coimbra, 1995).

A Psicologia, como profissão, ingressou na sociedade brasileira sob a égide de um sistema ditatorial e acabou por se fazer como um mecanismo de auxílio ao poder. Para tanto, criaram-se técnicas para adaptação do indivíduo com intuito de "tratar" qualquer um que não se encaixasse nos padrões impostos pelo poderio. Coimbra (1995) denomina esse momento da história da Psicologia no país como uma "psicologização", uma vez que os profissionais psi acabavam por fazer os indivíduos se 
adaptarem aos ditames da sociedade por meio de técnicas intimistas, cuja cientificidade era dubitável. Diz a autora: “...as categorias políticas são transformadas em categorias psicológicas, o importante não é o que se faz, mas o que se sente..." (p. 34).

Foi nesse cenário político do país e, considerando as transformações pelas quais passava a psicologia no âmbito internacional, em especial nos Estados Unidos, que em meados dos anos 1960, começaram a surgir as psicologias humanistas, assim denominadas por se colocarem em oposição aos modelos hegemônicos, tais como a Psicanálise e o Comportamentalismo (Rosa \& Kahalle, 2002), a fim de atender as demandas de questionamento da sociedade americana na época (Amatuzzi, 2010). Na década de 1970 vislumbra-se a introdução de alguns modelos teóricos no Brasil (Sacomano \& Faria, 2014), tais como o Aconselhamento Centrado na Pessoa, de Carl Rogers, o Psicodrama, de Jacob Levy Moreno, e a Gestalt-Terapia, de Friederich Perls, além das Terapias Corporais, que se apresentavam como um movimento inovador para a Psicologia.

Dito momento de inserção desse humanismo na psicologia mostrou que tal abordagem não se apresenta como uma teoria específica ou escola específica, mas como um fazer psicológico insatisfeito com as visões de homem anteriormente discorridas nas psicologias tradicionais da época. A psicologia humanista apareceu com um sentido grandioso, revelando o instante em que o humanismo se instalou na psicologia como ciência e profissão (Amatuzzi, 2010). A difusão do movimento humanista surgiu com propostas de intervenção psicológica que colocaram em pauta a discussão dos temas existenciais e do método fenomenológico. $\mathrm{O}$ estudo da consciência - com o método fenomenológico - conquistou uma posição central na psicologia contemporânea (Gauer \& Gomes \& Holanda, 2004).

Propor-se a uma pesquisa histórica de fonte documental requer um cuidado metodológico que exige, ao mesmo tempo, um distanciamento e uma proximidade. Em primeiro lugar o distanciamento do pesquisador que, ao voltar seu olhar para o passado, busca nele aquilo que lhe interessa mais diretamente - no caso desta pesquisa, a psicologia humanista. Em segundo lugar uma proximidade que é a de tentar resgatar o contexto histórico no qual se deu a produção do documento. Esse movimento de distanciamento e proximidade visa garantir a compreensão.

Compreender algo, segundo Dilthey (1860 citado por Palmer 1989), seria um ideal centrado no conhecimento ou no método. Entretanto, compreender algo a partir da hermenêutica de Gadamer significa permitir, por meio da interpretação, a possibilidade de visualizar coisas escondidas em um texto ou num gesto, por exemplo. Para isso, ao estabelecer um posicionamento de compreensão de um texto é necessário querer saber o que o mesmo traz. Desse modo, busca-se questionar o texto com o intuito de dialogar com o mesmo. Diz o autor que a estrutura rígida de um texto deve entrar num movimento do diálogo - sendo assim, não se deve ler um texto esperando que o mesmo se coloque de modo sustentável, porém sim de modo questionável. Segundo Palmer (1989),

As chaves para compreensão não são a manipulação e o controle, mas sim a participação e a abertura, não é o conhecimento, mas sim a experiência, não é a metodologia, mas sim a dialética. Para Gadamer, o objetivo da hermenêutica não é avançar com regras para uma compreensão objetivamente válida mas sim conceber a própria compreensão de modo tão lato quanto possível (p. 216).

\section{Objetivos}

A presente pesquisa buscou identificar conteúdos associados à Psicologia Humanista publicados na revista Psicologia Atual entre os anos 1977 e 1986. A partir dos conteúdos selecionados, buscou-se, ainda, identificar as diferentes teorias humanistas veiculadas pela revista, os seus proponentes e depreender significados dos conteúdos publicados.

\section{Procedimentos Metodológicos}

\section{Da fonte de pesquisa:}

Tratou-se de uma pesquisa documental, tomando como referência o fato de que a revista Psicologia Atual foi comercializada pela mídia escrita em bancas de revistas e disponibilizadas ao público em geral. Todos os volumes publicados encontram-se disponíveis para consulta na biblioteca da Pontifícia Universidade Católica de Campinas.

\section{Da seleção e organização dos conteúdos:}

Para a seleção dos conteúdos foram consideradas quaisquer inserções que contivessem, inicialmente, as seguintes palavras: Psicologia Humanista, fenomenologia, existencialismo, Gestalt-terapia, Terapia Centrada na Pessoa, Dasein Análise, Logoterapia, Psicodrama. Partindo dos princípios humanísticos presentes em tais abordagens teóricas, foram selecionadas, também, as inserções que apresentassem as seguintes palavras: tomada de consciência, criatividade, espontaneidade. Consideraram-se, ainda, referências diretas aos formuladores das teorias selecionadas. A partir desses critérios foram identificadas 30 inserções.

Foram classificados como artigos os conteúdos que se dispunham a fazer a difusão de conhecimentos psicológicos, sejam eles de caráter teóricos ou de pesquisas, cuja opinião do autor fosse explicitamente registrada, em número de 13 inserções. Outras 4 inserções foram denominadas como reportagens, cujo o conteúdo era de cunho informativo e analítico de temas diversos, com características 
de notícias. Por fim, 13 inserções de conteúdos que apresentavam a opinião ou o conhecimento de profissionais de Psicologia por meio de uma interlocução com o editor ou outros profissionais da área, foram classificadas como entrevistas.

\section{Da análise dos conteúdos:}

Os conteúdos foram analisados a partir do método hermenêutico proposto por Hans Georg Gadamer, o qual procura colocar em diálogo discussões científicas, ontológicas e ideológica de temporalidades distintas. Visando então criar esse diálogo com os dados, os conteúdos foram lidos em quatro momentos diferentes. O primeiro buscou identificar o autor, o tema e o enfoque teórico contido em cada uma das inserções; o segundo consistiu em buscar compreender como o autor enfocava o tema sobre o qual discorria e como o articulava com a teoria presente no conteúdo. No terceiro momento, o diálogo deu-se por meio de questionamento pelo próprio texto, além de depreender o sentido que o autor atribuía ao tema. Por fim, na quarta leitura, decorreu uma análise, na qual se buscou identificar quais respostas os textos traziam às questões feitas, articulando-as com momentos históricos distintos.

\section{Resultados}

Segundo a orientação metodológica indicada, entende-se que toda leitura faz-se como um exercício hermenêutico, uma vez que qualquer descrição de texto, como que se segue, já é uma interpretação que é orientada pelo interesse da pesquisa. Apresentamos, assim, uma descrição-analítica dos conteúdos de cada uma das inserções identificadas em nossa fonte:

\section{Os artigos}

No artigo O uso do psicodrama na Educação, de Maria Alice Vassimon (Psicologia Atual,1977, vol.4), a autora discorre sobre a possibilidade em melhorar a relação professor aluno. Conta como as técnicas psicodramáticas foram utilizadas com um grupo de professores e como estas contribuíram para a melhoria das relações de grupo e das percepções dos membros do grupo. Rachel L. Rosenberg assina o artigo $O$ velho e a família (Psicologia Atual, 1978, vol. 10). Nele é abordado o papel do velho junto à família: A autora enfoca a problemática que é criada perante a cristalização desse papel no contexto familiar que é catalisado pela negligência da sociedade para as questões singulares de cada indivíduo. Para essa discussão são utilizadas as referências da Abordagem Centrada na Pessoa.

Em Vocação: como saber o que é melhor para você? de Regina Cywinski e Iveth Cavalcante (Psicologia Atual, 1977, vol. 6), as autoras buscam demonstrar como se dá o trabalho do Psicodrama na orientação profissional.
Argumentam que as técnicas psicodramáticas auxiliam os indivíduos que estão inseguros com sua escolha de profissão a encontrarem uma diretriz, voltando-se para si mesmos: por meio de técnicas que favoreçam a auto percepção, trabalhada com jogos e dramatizações. O facilitador permite espaço para o indivíduo se conhecer de maneira mais sincera e íntima, além da observação e da percepção do mundo externo, junto a suas influências.

$\mathrm{O}$ artigo escrito pelo autor Décio Noronha, nomeado como Mitos da Gravidez: ser mãe é sofrer (e crescer) no aqui e no agora (Psicologia Atual, 1978, vol. 12), tem como tema central a construção de uma nova família, sendo ela apenas constituída ao nascer de um filho. Dialoga também sobre as frustrações reprimidas ao longo da vida devido aos papéis familiares, criticando o senso comum, representados por termos tais como: ser mãe é sofrer no Paraíso, ou amor, só de mãe. Todos esses estigmas, diz o autor, são falsos, pois retira do presente momento o vivido na construção da nova pessoa, que deixou de ser mulher e virou mãe, ou homem que deixou de ser marido e tornou-se pai. Ser mãe é sofrer no aqui-agora, no relacionamento. Ao abordar o tema, o autor trás consigo a sua concepção de família, a família nuclear burguesa. O Psicodrama de Moreno é utilizado para se discutir com a gestante o significado da gestação, analisando imagens estereotipadas sobre o parto e o relacionamento mãe-filho.

Achim Hermann Fuerstenthal é responsável pelo artigo Psicologia, Psicologia... (Psicologia Atual, 1981, vol. 18), em que apresenta uma crítica à maneira como se faz psicologia e ao modo como ela é ensinada nas academias. $\mathrm{O}$ autor compreende que a psicologia não deve ser vista como uma profissão que propicie, unicamente, o ganhar dinheiro, mas que sim deve ser compreendida como uma ciência do desenvolvimento humano. Afirma que os fenômenos trabalhados pela psicologia precisam ir além do simples falar do paciente: o que é dito por este está inserido num contexto maior - assim, o trabalho do psicólogo deveria ser espontâneo, singular e fundamentado epistemologicamente, como fenômenos.

Em E agora meu bem, o que diz o livro?, o psicólogo Pedro Prado (Psicologia Atual, 1980, vol. 18), partindo do princípio de que existe um diálogo sobre a relação sexual e o bem estar do ser humano integrado, questiona a dicotomia entre mente e corpo para o desenvolvimento desse bem-estar. A Abordagem Gestáltica é usada para ensaiar uma concepção de como o ser humano deve ser compreendido como um ser total, integral, não subdivido em diversas partes do corpo. Segundo o autor, não existe cabeça que faz a inteligência, ou corpo que tenha a boa performance, mas um ser integrado, dotado de prazeres e frustrações, capaz de sorrir e chorar, amar e odiar. A capacidade de conscientização do ser, podendo ter total percepção de seus sentimentos e necessidades, levaria ao caminho do humano saudável.

$\mathrm{O}$ artigo Existe uma terapia específica para problemas sexuais?, de autoria de Maria de Mello Azevedo e Walderez 
Bittencourt (Psicologia Atual, 1982, vol 26), defende que a terapia sexual não deve ser uma terapia fixada na capacidade e produção sexual do indivíduo, mas sim no indivíduo como um todo e em suas dificuldades. O texto tem como referencial teórico o Psicodrama de base Psicanalítica. Em Cesarino e Fonseca: início do Psicodrama, de Antonio Carlos Cesarino e José S. Fonseca Filho (Psicologia Atual, 1981, vol. 22) é relatada a influência do psicodrama argentino sobre o brasileiro e destacada a visita de alguns psicodramatistas argentinos ao Brasil, dentre eles Rojas Bermudez (afirmando que o responsável por montar uma cena de dramatização é o diretor-terapeuta) e Dalmiro Bustos (dizendo que os responsáveis pela dramatização são o paciente e o grupo). Tal influência contribuiu para o surgimento do interesse de muitos jovens pela área psicodramática - e a constituição da Sociedade Brasileira de Psicodrama leva-nos a pensar sobre como estava a relação política da época entre Brasil e Argentina.

No artigo Ana Verônica Mautner: terapia corporal (Psicologia Atual,1981, vol. 22), Mautner cita algumas influências para terapia corporal, como o Congresso Internacional de Psicodrama, a linha humanística com seguidores de Rogers, da Gestalt-terapia, e como Petho Sandor, um junguiano, se utilizava de técnicas corporais. Em seguida a autora fala sobre a formação de um Terapeuta Corporal, que deve partir da formação mínima de terapeuta geral, exemplificando com o curso de formação do Sedes Sapientiae e que ensina a teoria freudiana, passando pelo o estudo da análise do caráter, chegando à Vegetoterapia de Reich. Destaca, por fim, a possibilidade de acesso ao inconsciente por meio das técnicas corporais. Desse modo, a autora evidencia a relação da psicologia humanista com as técnicas corporais.

Denise Gimenez Ramos, Regina Chnaiderman e Dalmiro Bustos defendem em Terapeutas que transam com as pacientes: o complicado destino das relações desiguais (Psicologia Atual, 1982, vol. 27) a ideia de que a partir do momento em que o terapeuta tenta suprir suas necessidades amorosas com seu paciente, a terapia termina. Dizem que os pacientes não se apaixonam pelo analista, mas sim por um aspecto de si que projeta nele. Para os autores, o papel do terapeuta seria o de ajudar a paciente a entrar em contato com mecanismos de cura que o próprio paciente tem dentro de si, contribuindo para a totalidade do self do paciente guiar o processo. $\mathrm{O}$ desejo sexual do paciente pelo analista resultaria da tentativa de agradar e satisfazer os desejos do terapeuta ao invés de "mergulhar em seu inconsciente", diz o artigo. O terapeuta "salvador" se interporia entre a totalidade do paciente e seu ego.

No artigo Arte \& Vida: Vida moderna: Afinal, o cigarro ajuda ou atrapalha as relações humanas? (Psicologia Atual, 1982, vol. 27), Arthur Kaufman narra uma sessão de psicoterapia, na qual se faz uso de técnicas psicodramáticas, como a troca de papéis com sua paciente, entre ela e o cigarro que fuma. Conta que mostrava a ela que seu vício contribuía para ela encobertar problemas de relações pessoais e sociais. Em seguida, o terapeuta fazia a paciente vivenciar o que buscava no ato de fumar, que era ficar sozinha num lugar escuro e quente, onde poderia permanecer fora de foco. Após a sessão a paciente relata não sentir mais vontade de fumar, justificando sua modificação sensitiva por ter vivenciado o momento que tanto buscava com o cigarro - que era se sentir isolada do convívio social, o que lhe dava a sensação de proteção e conforto.

Em Crise e cuca: os novos caminhos da auto-realização (Psicologia Atual, 1983, vol. 37), a autora Ana Verônica Mautner critica o movimento pós-revolução tecnológica em relação a mudanças de valores que a humanidade sofre. A proposta é de que não se deve seguir o modelo capitalista de promover ambição excessiva ao consumo. Não se deve ter muito para se obter segurança, conforto, felicidade etc. Para a autora, tais qualidades teriam que ser criativas, mas para isso acontecer seria necessário entrar em contato com a historicidade das concepções de trabalho, por exemplo, que mudaram depois da revolução tecnológica. Antes as pessoas trabalhavam em profissões tradicionais e, naquele hoje, tentavam buscar significado em seu trabalho. Segundo a autora, o teórico Maslow se equivoca ao defender a ideia de que o ser humano consegue se realizar por ele mesmo e assim alcançar a felicidade.

Por fim, o artigo de Denise Ramos E como rejeitar o medo de ser rejeitado? (Psicologia Atual, 1986, vol. 42), fala do medo do indivíduo de vivenciar uma solidão afetiva. Diz que para enfrentar a solidão é preciso o indivíduo vivenciá-la e não, ao contrário, tentar esquecê-la, pois só assim ele conhece o significado da solidão e passa a conhecer a si mesmo. O estado do solitário é o de isolamento de si mesmo, de sua totalidade. Segundo o junguiano Ian Baker, solidão refere-se ao isolamento de espírito que bloqueia o impulso de alcançar o outro.

\section{As entrevistas:}

A publicação de Paulo Gaudêncio, Paulo Gaudêncio, Outra Vez Tv (Psicologia Atual, 1978, vol. 10), discute seu programa televisivo que tem como tema um diálogo sobre as dificuldades psíquicas que são debatidas por meio de um programa de televisão, totalmente espontâneo. O programa, supervisionado pelo psiquiatra, era uma simulação de um grupo de terapia. Denominado como O Grupo, o mesmo trazia para a televisão situações do cotidiano de indivíduos com distúrbios psíquicos e a forma como esses distúrbios eram trabalhados. Gaudêncio afirma que o programa nunca teve o intuito de ser uma terapia televisionada, ou uma terapia via meios de comunicação, mas sim uma forma de propagação da informação. Dessa maneira, o telespectador poderia compreender que existem diversas formas de trabalhar suas dificuldades, fugindo do modelo biomédico. Para ele, qualquer um que se reconhecesse com os trabalhos poderia buscar ajuda 
da maneira correta: as teorias humanistas estão ligadas apenas ao desejo do supervisor em ter consigo psicólogos psicodramatistas e gesltalt-terapeutas no programa.

Na entrevista concedida por Rachel L. Rosenberg, publicada sob o título de Indivíduo, Família, Casamento (Psicologia Atual, 1982, vol. 34), a entrevistada fala sobre o mito familiar junto à construção de indivíduos e que estes estariam insatisfeitos com seus cotidianos. A teórica Rachel tenta trazer à tona as questões da confluência e da negligência entre os componentes da estrutura familiar. Sempre mantendo o equilíbrio como conceito central, a mesma demonstra que os extremos são os problemas, e que a busca deveria ser sempre pela equiparação entre ambos. Para ela, da mesma forma que a total liberdade levaria ao caos, a confluência, ou, em outras palavras, a cobrança excessiva em que o casal perde a concepção da individualidade, ignorando o self de cada um, desemboca em diversas cobranças desgastantes com um único resultado: a perda do prazer em estar próximo.

As vantagens e os limites da liberdade infantil é o nome da entrevista de Maria de Mello Azevedo, (Psicologia Atual, 1982, vol. 29), na qual se dialoga sobre a influência dos pais na educação do filho. Por meio de uma análise do passado e do presente, a entrevista explora ideias sobre como deve ser a postura dos pais perante a educação da criança. A entrevistada conclui que os extremos, isto é, cuidado excessivo e negligência, são ambos problemáticos, sendo necessária uma busca pelo equilíbrio. Os termos "cabes baixa" e "nariz pro ar" são frequentemente usados como maneira de denominar, o primeiro a criança resultante de uma educação ditatorial, e o segundo uma criança totalmente livre. A criança "cabes baixa", citada por ela, era a denominação da incapaz de ser espontânea, impedindo que sua essência viesse à tona. O seu antônimo, que a autora nomeia como "nariz pro ar" é a incapaz de se reconhecer dentro de sua fronteira de contato, não notando suas limitações entre seu self e o mundo. A liberdade demasiada resultaria em pessoas assim, incapazes de reconhecer o semelhante. Para ela, esses tipos de pessoas citados durante toda a entrevista são os resultados dos novos paradigmas mal internalizados na época, gerando sempre uma dificuldade. Essas mesmas demandas não alterariam apenas os novos educados, mas o papel social há décadas já existente, como o ser mãe, pai, escola.

O padre Edênio Valle fala da psicologia da religião na entrevista $O$ Deus perdido numa noite suja (Psicologia Atual, 1982, vol. 35), que estaria, segundo ele, voltada a discutir a fé, não enquanto realidade sobrenatural, mas como vivência do Homem e sua repercussão no comportamento humano. Aponta o entrevistado uma peça de Plínio Marcos (Dois perdidos numa noite suja) como uma parábola cristã em que se conta a história de dois homens que passam por dificuldades na vida. $\mathrm{O}$ autor generaliza dizendo que para "encontrar" Deus na vida, é preciso passar por "noites sujas", assim como as personagens da peça. Para ele, a dificuldade da vida atribui-se exclusivamente ao próprio indivíduo. Adiante, menciona Freud, Sartre e Heidegger ao abordar duas experiências fundamentais na vida humana, a de vida e a de morte.

\section{As reportagens:}

Arthur Kaufman, em Doença mental, questão de família (Psicologia Atual, 1977, vol. 4), fala do trabalho e da visita do psiquiatra Ronald Laing ao Brasil difundindo ideias da Antipsiquiatria, movimento que defendia que a doença mental não poderia ser compreendida exclusivamente a partir do indivíduo, mas sim como fruto de uma interação de fatores que começaria na família, perpassaria o meio social e terminaria com o sistema político. O texto deixa claro, entretanto, que a "doença mental é vista, então, como uma patologia dos vínculos existentes entre as pessoas" (p. 51). A reportagem resgata um histórico acerca da doença mental, afirmando que o tema sempre oscilou entre a perspectiva psicossocial e a organicista. $\mathrm{O}$ autor cita alguns teóricos, tais como Karl Jaspers, um psiquiatra discípulo de Husserl que introduz a fenomenologia no estudo da patologia mental; Biswanger, com a fenomenologia existencial tentando caracterizar a experiência do doente mental e Malinowski, do nascimento da Antropologia Cultural. A reportagem deixa claro que a Antipsiquiatria tem raízes na Psicanálise, na Fenomenologia existencial e na Antropologia Cultural.

Medard Boss, o criador da Análise Existencial (Psicologia Atual, 1977, vol. 4), faz a transposição da filosofia de Heidegger para "uma consistente análise do homem". Diz a reportagem que, em uma entrevista ao "Jornal da Tarde", Boss teria afirmado que todos os problemas humanos podem ser definidos como forma de restrição da abertura para o existir humano. Toda relação humana estaria, segundo ele, na relação de se abrir para o mundo. $\mathrm{Na}$ Daseinsanalys e ("ser ai", "ser no mundo"), exemplifica o autor, o tratamento é diferente na duração e nas características da terapia, que dependem daquilo que o doente quer tornar-se. Se ele deseja ser livre, ser dono de suas "faculdades", a análise pode durar algumas sessões, apenas até o desaparecimento de alguns sintomas. Em outros casos, a terapia pode durar dois, três ou até quatro anos - ainda assim um tratamento mais rápido do que em outras psicoterapias.

Mauren Miller em Belo Horizonte (Psicologia Atual, 1977, vol. 4) relata a visita de Mauren Miller (formada pelo Gestalt Institute of Cleveland) à Sociedade Mineira de Psicologia, em Belo Horizonte. A visitante conduziu o "Grupo de Desenvolvimento Pessoal” para universitários dos primeiros períodos de graduação e profissionais interessados em adquirir maior conhecimento de si e novas maneiras de se relacionar. A reportagem relata, ainda, que ela conduziu um Grupo de Treinamento com alunos do último ano de graduação e profissionais ligados ao desenvolvimento da pessoa humana (psicólogos, assistentes sociais, psiquiatras). 
Walter Andrada Parreira, na reportagem O IV Congresso de Psicologia Transpessoal (Psicologia Atual, 1977, vol. 4), discorre sobre a realização do IV Congresso de Psicologia Transpessoal em Belo Horizontee faz referências a participantes ilustres do Congresso, dentre eles Ronald Laing, um dos pais da Antipsiquiatria e Leo Matos, brasileiro especializado em Gestalt Terapia. Apresenta, então, a Psicologia Transpessoal como quarta força da psicologia, justificando-se pelo fato de que a mesma se desvinculava do modelo limitado em que as outras forças (Behaviorismo, Psicanálise e Humanística) tinham em relação às potencialidades e capacidades do ser humano de ser e agir no mundo. Parreira ainda diz que tal congresso apresenta a Transpessoal como distinta dos demais métodos da psicologia ocidental, como o Experimental, o Psicanalítico, ou o Fenomenológico e aborda métodos orientais, como o Zen, a Ioga, o Supismo, afirmando estes se apoiarem em outras ciências, como a Antropologia, a Sociologia, a Neurologia e a Física.

Em William Hollaway em São Paulo (Psicologia Atual, 1978, vol. 5) é divulgada a visita do psicólogo William Hollaway, especialista em análise transacional, o qual vem a São Paulo no ano de 1978 e dá dois cursos. O primeiro, Curso Avançado de Formação AT/Gestáltica, inclui teorias tanto da "AT quanto da terapia Gestáltica mostrando semelhanças e diferenças entre os dois métodos de tratamento”. O segundo consiste em "Técnicas específicas em psicoterapia”, no qual se trabalharam técnicas como fantasias estruturadas, trabalho com o sonho, modelagem familiar etc. Os dois cursos foram apresentados no IBT (Instituto Brasileiro de Análise Transacional).

Sem especificação de autoria, a revista reporta Em psicoterapia, quando alguém está curado? (Psicologia Atual, 1978, vol. 9) o fato de que o indivíduo estaria curado quando soubesse reivindicar, tranquilamente, os seus direitos, quando fosse capaz de atingir as próprias metas mesmo que fosse preciso combater algo ou confrontar pessoas. Essa perspectiva de cura, segundo a reportagem, é uma das conclusões do Segundo Congresso Brasileiro de Análise Transacional; as demais conclusões do evento giram em torno de características da terapia, que seriam as técnicas provenientes de outras correntes em psicoterapia, como a Psicanálise, o Comportamentalismo, a Psicodança, a Bioenergética, a Gestalt-terapia e o Psicodrama. Faz-se referência às teorias humanistas, portanto, como meio de técnicas para Análise Transacional.

O psicanalista Oscar Cesarotto, autor da reportagem Masotta e Bion. As grandes perdas de 79 (Psicologia Atual, 1979, vol. 12) relembra a trajetória de Oscar Masotta, introdutor de Lacan, e de Wilfred Ruprecht Bion,que morreram em 1979. Cesarotto articula influências do existencialismo de Sartre, da década de 1950 coma fenomenologia de Merleau-Ponty e Daniel Lagache. Segundo a Reportagem, Masotta foi influenciado tanto por Pichon Riviere quanto pelas ideias de Lacan. Sobre Bion, o autor argumenta que com suas influências na psicanálise diante de suas experiências de trabalho ele o desenvolvia a partir de suas práticas, tomando como notoriedade maior sua participação com grupos de soldados vítimas de "neurose de guerra". Alguns psicanalistas destacam sua importância à obra Os elementos da psicanálise por meio da Fenomenologia do Espírito de Hegel.

A reportagem Recursos Humanos (Psicologia Atual, 1979, vol. 15) apresenta o Nono Congresso Mundial de Treinamento e Desenvolvimento e fala sobre conferências nele realizadas, tais quais: Sub-educação - um risco a ser evitado (Pedro Demo, do MEC); Treinamento no Brasil: Ideologia e prática (Laura Dantas, do IUPEERJ); Raízes do poder nas instituições empresariais (Juan Jose Mouriño Mosquera, da UFRS); Análise Psicológica do processo decisório (Milton de Oliveira); Pesquisas de Validação da Teoria de Liderança situacional no Brasil e nos EUA (Michel e Sophia Caracushansky) e Desenvolvimento do papel profissional através de recursos Psicodramáticos (Antonio Gonçalves dos Santos).

José Roberto Alternfelder Silva Wolff usa o espaço de publicação para falar do Onirodrama (Psicologia Atual, 1980, vol. 20). Nessa reportagem, ele aborda o Onirodrama desenvolvido por Moreno nos seus primeiros estudos e a continuação dada pelo autor sobre o assunto. Tal conceito parte do pressuposto de o indivíduo interpretar seu sonho e não apenas de relatá-lo durante a terapia. Wolff afirma que esta foi a primeira vez que alguém se especificou no assunto, até então muito vago na teoria de Moreno.

O psiquiatra José Angelo Gaiarsa em Uma escola livre de psicoterapia (Psicologia Atual, 1981, vol. 24) utiliza o espaço da revista para falar sobre o "grupo sem palavras", o qual visa uma interação comunicativa não-verbal com um grupo de pessoas. $\mathrm{O}$ autor defende um ideal terapêutico com tal grupo, com a pretensão de manter um vínculo de amizade entre os clientes, o qual possibilitaria ver aspectos problemáticos de si por meio do outro. Ao referenciar seu ideal terapêutico, o autor deixa incógnitas sobre o que é, de fato, seu posicionamento a respeito do fazer terapêutico, uma vez que o "grupo sem palavras" mais parece um grupo de socialização do que terapêutico. A Gestalt aparece, em sua reportagem, como técnica corporal a ser aplicada com o intuito de se estabelecer uma relação amorosa entre indivíduos.

Oswaldo di Loreto, psiquiatra, é o autor de Uma Terapia com Crianças Injustiçadas (Psicologia Atual, 1982, vol. 33). Sua reportagem aborda um método de psicoterapia psicossocial, desenvolvida pelo grupo no qual di Loreto encontra-se inserido. $\mathrm{O}$ autor relata um projeto de intervenção para crianças em situação de risco, como violência, pobreza ou maus-tratos. Em todo momento, ele deixa bem claro que o projeto é interventivo e experimental e que passa longe de um assistencialismo.

A reportagem com Arthur Wassmer foi realizada para dialogar sobre um livro publicado pelo mesmo havia pouco tempo. Ela foi denominada Vencendo a Timidez (Psicologia Atual, 1986, vol. 45) e trabalhou com uma 
visão do autor Carl Rogers para compreender e desenvolver atividades com um indivíduo caracterizado como tímido. Segundo Rogers, a timidez estaria diretamente relacionada com a dificuldade do ser humano em ouvir o próximo e não com o temor pelo julgamento, como comumente se acredita. Para ele, o indivíduo que não tem condições de realizar uma escuta é responsável pela sua própria timidez.

A psicóloga clínica Amaryllis Schvinger discorre na introdução da reportagem Grupomania (Psicologia Atual, 1982, vol. 35) sobre novas técnicas terapêuticas que foram surgindo após a consolidação das duas técnicas predominantes, que segundo a psicóloga seriam a Psicanálise e a Terapia de Apoio. Essas novas técnicas seriam as da Abordagem Centrada na Pessoa (baseadas nas teorias de Carl Rogers e nas dos Neo-freudianos), assim como aquelas sob influência dos terapeutas estrangeiros (Terapia de Crise, Terapia Breve, a de gestantes), a Terapia da Gestalt, o Psicodrama, a Bioenergética etc. Para Schvinger, essas novas técnicas mudaram o aspecto quase monolítico da psicoterapia. Em seguida, a autora se refere à mania de algumas pessoas que passam de um grupo terapêutico para outro, o que prejudica o aprimoramento das experiências propostas nos grupos.

\section{Discussão}

Foi possível observar que todas as inserções tendiam a falar de temas relacionados ao cotidiano do brasileiro contemporâneo nos anos das publicações. Identificou-se, ainda, uma possível proximidade entre os temas abordados para dialogar com os leitores da revista, sugerindo a possibilidade da criação de categorias analíticas. Foram construídas seis categorias analíticas, sendo elas: Família, Interioridade, Sexualidade, Trabalho, Visitas e Outros. Denominou-se como Outros uma gama de temas que não se referiam às categorias anteriormente citadas e que se apresentavam em menos de três inserções.

Entenderam-se por Família as menções a um grupo de referência no ciclo vital das pessoas, fossem elas dadas por consanguinidade ou aproximações culturais e/ou afetivas. Alocaram-se na categoria Interioridade as referências que traziam a ideia de uma busca de construção e compreensão da pessoa apenas por meio de seus componentes singulares.

Como Sexualidade foram classificadas quaisquer referências aos valores atribuídos aos papeis sexuais, assim como leituras sobre o próprio ato sexual. Denominaram-se como Trabalho os conteúdos que continham quaisquer tipos de informações sobre a relação homem-trabalho, logo, o indivíduo e suas relações de produção.

O tema Visitas abordou todas as referências que continham a informação da visita de algum teórico eminente, palestrante ou psicólogo estrangeiro ao Brasil. Por fim, o espaço Outros abarcou, como já mencionado, os temas que não se encaixaram em nenhumas das categorias anteriores.

Para alocar todas as publicações selecionadas, realizou-se uma revisão das segundas leituras conforme descrito no item Organização dos Conteúdos. Para um tema ser definido como categoria, foi necessário ocorrer a aproximação de três ou mais publicações que o abordassem. As inserções não foram agrupadas, necessariamente, em apenas uma categoria, possibilitando que o mesmo texto esteja contido em duas ou mais sessões. Após esse momento foi observado e analisado como as inserções dialogavam sobre os temas da época, como se vê na Tabela 1:

Tabela 1: Aparições de Categorias por Inserções

\begin{tabular}{|l|c|c|c|c|c|c|}
\hline & Família & $\begin{array}{c}\text { Interio- } \\
\text { ridade }\end{array}$ & $\begin{array}{c}\text { Sexua- } \\
\text { lidade }\end{array}$ & $\begin{array}{c}\text { Traba- } \\
\text { lho }\end{array}$ & Visita & Outros \\
\hline Artigos & 2 & 5 & 4 & 5 & 0 & 3 \\
\hline Entrevistas & 2 & 3 & 0 & 0 & 0 & 2 \\
\hline Reportagens & 0 & 4 & 0 & 1 & 4 & 7 \\
\hline Total & 4 & 12 & 4 & 6 & 4 & 12 \\
\hline
\end{tabular}

A partir dessas leituras, tornou-se possível identificar determinadas concepções de família, intimidades, sexualidade e constituição de homem, tanto no âmbito particular como no social - por exemplo, no trabalho. Todas essas concepções contemporâneas às publicações relacionavam-se em um ponto em comum: a valorização do individual e o esvaziamento da vida política. Nas discussões sobre a constituição familiar, notou-se um caractere de família nuclear burguesa, modelo esse que provém do século XVI, com o aparecimento do conceito de infância e com o advento da burguesia. Provido de aspectos constituídos pela classe burguesa, a família nuclear trouxe consigo caracteres como a valorização da privacidade, o amor conjugal e monogâmico, o dever de proteger a prole e de educá-la para perpetuar os ideais familiares. Nas publicações estudadas, nota-se que os autores transparecem uma ideia de que uma nova família era constituída apenas ao nascer de um filho, como, por exemplo, no artigo Mitos da gravidez: ser mãe é sofrer (e crescer) no aqui e agora, de Décio Noronha, em que o autor afirma que:

Para situar bem o problema é preciso considerar também que da gravidez, do parto, não resulta somente um nascimento, resultam quatro. Nasce uma criança, nasce uma mulher para o papel de mãe e um homem para o papel de pai. Nasce uma família (...) Se antes tinha um marido-amante, agora ele também é pai assim como ela é mãe: surgiu uma família (...) Para a família, a criança significa a sedimentação de seu núcleo. Um ser novo sempre reforça o sentimento de família (p. 16).

Dessa maneira, destaca-se do artigo que a família a que o autor se refere remete a uma concepção hegemônica à 
época e privilegiado por uma sociedade ditatorial, como a do regime militar, facilitando o sistema de controle social. Ainda na categoria Família, foi possível depreender alusões acerca de papéis familiares que se revelam na medida em que algumas inserções estabeleciam "padrões" a serem seguidos pelas personagens de uma família. No volume 29, na Entrevista As vantagens e os limites da liberdade infantil, de Maria de Melo Azevedo, fala-se da função dos pais como estabelecedores de limites aos filhos. Ademais, na revista de número 12, em Mitos da gravidez: ser mãe é sofrer (e crescer) no aqui e agora, Décio Noronha discorre sobre os papéis familiares, dizendo que estes se somam e se confundem ao longo da vida, o que pode gerar conflitos pessoais e/ou intrafamiliares, quando os atores se apegam a um estereótipo desses papéis.

Os papéis familiares foram abordados no artigo de Rachel Rosemberg $O$ velho e a família, os quais, segundo ela, estariam relacionados às diferentes fases da vida. A autora critica a visão de que o homem só tem valor durante sua fase produtiva, à maneira do capitalismo, atendendo às expectativas de mercado. Na fase adulta, por exemplo, espera-se que o indivíduo tenha estabelecido sua posição social, econômica e profissional. Sua crítica firma-se na ideia de que o envelhecimento constitui uma fase da vida, ou seja, para Rachel a transição da fase adulta para a terceira fase da vida prende-se a um discurso de que esse processo envolveria o desenvolvimento de novas necessidades orgânicas, psíquicas e sociais, no entanto, diz ela "trata-se de perdas da vida adulta e não necessariamente da condição humana como um todo” (p. 40).

Outro trabalho de Rachel Rosenberg, também inserido na categoria Família, foi Indivíduo, família e casamento, publicado na Revista de número 19. No artigo, a autora discute o papel social do que é ser mulher ou homem dentro de um casamento, ou como é ser casal, dentro de um ato de confluência, e defende que ele se prende a estigmas perpetuados como ideais. Em determinado momento a autora ao comentar o casamento com a pessoa escolhida, diz "vamos fazer o que a gente quiser e vamos querer sempre a mesma coisa (...) o casamento vai preencher todas minhas necessidades, tanto a de pertencer a alguém, a uma família, como a de fazer o que eu quero" (p. 44).

Nota-se, aqui, uma afirmação dos papéis citados anteriormente, ou seja, como deveria ser a vida do bom casal. A mesma afirmação abrange também a discussão de como era o indivíduo saudável da época, padronizado por uma influência social. Para ser tido como alguém bom para a sociedade, o homem deveria cumprir seu papel social de casar, amar a cônjuge e, acima tudo, reduzir-se ao âmbito familiar, no qual teria poder de influência.

A redução do indivíduo a si mesmo era uma concepção de subjetividade constantemente pregada para o brasileiro da época. Percebe-se isso ao olhar-se para a categoria Interioridade, que permite a compreensão de um panorama geral das publicações, uma manifestação por algo pertencente ao interior das pessoas, como se essa interioridade não contemplasse questões culturais que a elas lhes constituíssem. Tal concepção de subjetividade remete a um subjetivismo no qual a pessoa é tratada como redentora de problemáticas vivenciadas, dando a entender que algo relativo ao "interior" seria relacionado ao sentimento de culpa, como se o indivíduo fosse exclusivamente responsável por sua ação no mundo. A subjetividade, vista assim, desconsidera os eventos culturais, tais como a política, a economia ou a religião.

No artigo Vocação: como saber o que é melhor para você?, de Regina Cywinski e Iveth Cavalcante, nota-se claramente como a psicologia buscava colocar no indivíduo a responsabilidade por sua frustração ou por seu sucesso no âmbito profissional. As autoras afirmam que o sujeito que passa por um momento de empregabilidade deve voltar-se para si buscando um autoconhecimento para enfim se alocar na "profissão ideal". Seguindo os passos citados por elas no artigo, o indivíduo estaria evoluindo num método “adequado” para obter o sucesso. Já na inserção categorizada como Reportagem Vencendo a timidez, de Arthur Wassmer, retrata-se esse aspecto intimista em trechos como "A timidez torna-se uma prisão cujo arquiteto é o próprio tímido” (p. 12). Dessa forma, o sujeito passaria a ser responsável pela sua própria timidez. E na inserção $O$ deus perdido numa noite suja, o padre Edênio Valle também confirma a presente análise no trecho: "o indivíduo fica muito voltado para si próprio, fascinado com sua própria experiência” (p. 16).

O contexto social contemporâneo dessa visão intimista do homem sofre grande força da repressão por parte da ditadura militar. Nesse momento, o âmbito social/público foi negligenciado, desvalorizando-se o "o que se faz", fortalecendo-se o "o que se sente" e assim criando-se uma psicologização da vida social. O dever do indivíduo passa a ser "lutar pelas suas particularidades", em detrimento de qualquer manifesto social na década de 1970. Foi exatamente nesse período que se alavancou a aparição de uma psicologia para tudo, denominada como "psicologismo". Essas diversas psicologias, demarcadas para suprir qualquer tipo de demanda, servia como mecanismo para readaptar o indivíduo desajustado, fortalecendo o intimismo (Coimbra, 1995).

A redução do indivíduo a si mesmo alcançou o âmbito da sexualidade do período estudado. Diversas terapias foram criadas para buscar o ápice da performance sexual, almejando a maior expressão de liberdade da pessoa. Em todas as leituras sobre o tema foi possível identificar uma concepção pragmática sobre o sexo, ou os papéis sexuais, que eram compreendidos como um ato repleto de estigmas, com o homem como símbolo de virilidade e a mulher de maternidade. As influências da ditadura militar refletiam nas relações dos casais, na relação de poder dentro do ato sexual (Coimbra, 1995). Tal aspecto foi observado na crítica realizada por Décio Noronha na inserção Mitos da Gravidez, ser mãe é sofrer (e crescer) no aqui e no agora, quando o autor ironiza a ideia corrente 
da época de que o papel do homem é estigmatizado pelo dever de manter sua virilidade em alta constantemente em detrimento da sua condição de paternidade enquanto, por outro lado, a mulher, cansada pelos cuidados básicos dispensados aos filhos tem seu interesse sexual reduzido. Esse homem buscaria na traição o método para cumprir seu papel viril. A crítica apresentada pelo autor sugere a existência de tensões entre os desejos individuais e os papéis sociais a serem cumpridos.

A satisfação sexual estava tão relacionada com as influências sociais que Pedro Prado, em E agora meu bem, o que diz o livro?, comenta que a impossibilidade das pessoas viverem a seu modo e a consequente busca de liberdade são os motivos pelos quais a maioria dos pacientes procuram por psicólogos, diz ele "há tempos, o prazer, a criatividade (...) a energia sexual e a possibilidade de desempenhar uma função social fecunda vêm sendo, de muitas formas, reprimidas (...) O que cada pessoa mais quer é poder acontecer do seu jeito no mundo" (p. 38)

Todavia, é impossível ao indivíduo chegar a essa libertação sexual sem alcançar anteriormente uma satisfação com seu todo. O autor confirma isso quando diz: "É fundamental fazer exercícios de relaxamento da pélvis, completam alguns especialistas. E tanto leigos como profissionais falam. Às vezes, como se pênis, vagina e pélvis poucos tivessem a ver com o conjunto do ser humano" (p. 38). As Terapias Corporais ganharam enorme força com a impossibilidade da expressão de liberdade do indivíduo no campo político-social. Para idealizar a sensação de liberdade, pregava-se a busca por uma satisfação apenas no nível corporal como a solução para o desenvolvimento sadio do indivíduo.

O Trabalho também era compreendido a partir de um viés intimista no qual o indivíduo deveria ser responsável para preparar-se para o mundo competitivo do mercado, que era dado pela produção e pelo consumo. O saudável, assim visto, era o indivíduo capaz de estabilizar-se no mundo do trabalho, tornando-se produtivo, com o objetivo de garantir sua sobrevivência e a de sua família, além de acumular bens. Isto posto, identifica-se que o trabalho é reduzido a mera técnica para adaptar o sujeito à vida produtiva construída por meio da especialização, como se nota, por exemplo, no artigo Vocação: como saber o que é melhor para você, que indica que o indivíduo que passa por um processo de formação escolar encontrará sua vocação para o seu futuro profissional. Como estudantes do ensino fundamental, aquele que está na busca pela escolha de uma profissão, deverá retornar a si mesmo afim de identificar suas habilidades. O artigo Crise e Cuca: os novos caminhos da auto-realização, por outro lado, faz uma crítica à concepção de trabalho que a Psicologia estava divulgando, servindo como um mecanismo da crise econômica vivida no país, no qual se construíam indivíduos direcionados à produção e ao consumo.

A própria Psicologia, como profissão, também é alvo de crítica devido ao fato de o psicólogo, muitas vezes, centrar sua atuação nos honorários e não na busca do desenvolvimento humano. O artigo Psicologia, Psicologia..., de Achim Hermann Fuerstenthal, critica esse modo de fazer psicologia apresentando um discurso mais abrangente, ao considerar a epistemologia e a ontologia, que envolvem essa área de trabalho (Psicologia Atual, 1980, p. 51).

Para um país que se encontrava em forte processo de industrialização, com a importação de tecnologias das mais diversas, fossem elas industriais, científicas, educacionais, dentre outras, não foi diferente o caso da Psicologia. As inserções que ocuparam a categoria Visita relatavam a presença de alguns eminentes psicólogos estrangeiros em território nacional. Em Medard Boss: o criador da Análise Existencial, contava-se a visita de Boss e trazia-se um relato do mesmo para o Jornal da Tarde. Na publicação Mauren Miller em Belo Horizonte estava contido um relato sobre a visita de Mauren Miller para conduzir dois grupos de desenvolvimento de pessoas. A última inserção que relatava uma visita foi William Hollaway em São Paulo, autor que veio ao país para coordenar curso no Instituto Brasileiro de Análise Transacional.

\section{Considerações finais}

Quase quatro décadas depois do início da circulação da revista Psicologia Atual, observam-se transformações significativas pelas quais passou a sociedade brasileira e, consequentemente, a psicologia e o fazer psicológico no país. Por meio de um recurso hermenêutico, é-nos possível estabelecer um diálogo entre o presente e o passado e traçarmos algumas comparações entre temporalidades distintas para compreendermos a constituição da subjetividade.

Se o regime militar estabeleceu uma ordem política ao modo de vida dos brasileiros, impedindo-lhes o direito de livre expressão, censurando as expressões artísticas, determinado os caminhos da educação tentando construir indivíduos dóceis à sociedade de consumo, hoje identificamos a homogeneização do modo vida ditado não mais pelo regime militar, mas por uma economia globalizada que acaba, da mesma forma, adaptando o indivíduo a modelos considerados mais adequados ao consumo. Essas transformações permitiram, por outro lado, que se aflorassem diferentes concepções de mundo, sejam elas dadas por modelos científicos, políticos ou religiosos, dentre outros, que vão se firmar em forma de valores que, distintamente, orientarão a vida cotidiana dos indivíduos. Destacamos, como exemplo, o modelo de família registrado nas publicações estudadas e que é o hegemônico da época, qual seja, o da família nuclear burguesa; atualmente a noção de família parece ampliada: podemos citar as famílias homoafetivas, as monoparentais e as recompostas.

As constituições familiares atuais, entendemos, encontram-se em diálogo com a sexualidade, que por sua vez ganhou novas nuances, assim como os próprios papéis 
sexuais. Em primeiro lugar, vale destacar a condição feminina: a mulher passou por um processo de maior inserção no mundo do trabalho e viu ocorrerem mudanças no modo de viver a sua sexualidade. A mulher contemporânea, em sua maioria, dedica-se ao trabalho e à vida familiar, além de ter seus interesses sexuais reconhecidos. A condição masculina também se transformou: o homem passou a compartilhar os cuidados do lar e da educação dos filhos. As relações homoafetivas parecem ganhar sua relevância no cenário atual, decorrente de movimentos sociais que só conquistaram visibilidade após o período estudado.

O trabalho exposto nas inserções estudadas refere-se a um desenvolvimento tecnológico emergente ao qual todos deveriam se adaptar por meio de uma educação voltada à inserção no mercado de trabalho; assim sendo, negligenciava-se a formação do indivíduo consciente de seu lugar social, direcionando-o à produção e ao acúmulo de bens. Essas propostas educacionais focavam-se na identificação e no desenvolvimento de habilidades pessoais, voltadas para a preparação do indivíduo para o mundo do trabalho. Nos dias atuais, em que se considere todo o aparato tecnológico de ensino, a educação mantém seu propósito de preparar o indivíduo para se submeter ao mundo competitivo do mercado.

Ressalta-se a perspectiva intimista com que textos estudados enfocam temas sociais relevantes, como a família, a sexualidade e o trabalho; ao valorizarem a intimidade, acabam por "subjetivar" a vida social, perdendo, assim, a dimensão política da época. As quatro décadas que se passaram parecem não haver assistido a uma transformação nessa compreensão de indivíduo. As novas tecnologias da informação presentes nos nossos dias, ditas como mecanismos de aproximação dos indivíduos, acabam por favorecer o isolamento, o distanciamento e o intimismo, perpetuando, assim, o esvaziamento da vida coletiva.

As produções científicas em psicologia tiveram um aumento significativo sustentado pelo crescimento dos cursos de graduação e pós-graduação em psicologia. $\mathrm{O}$ desenvolvimento de pesquisas nacionais objetivou a construção de uma psicologia que estivesse mais comprometida com os problemas e o modo de vida do brasileiro, desta forma possibilitando diálogo com produções internacionais e não apenas a reprodução destes. É notório, de um modo geral, um discurso da psicologia humanista em colocar-se como um diferencial das tendências psicológicas hegemônicas da época, em especial o de emancipar o indivíduo; todavia é evidente, também, que o modo como concebe a família, a sexualidade, a intimidade e o trabalho, visa adaptá-lo às condições sociais da época. Um discurso que, estruturado sob a égide da novidade, buscaria refletir sobre as dificuldades e os limites da sociedade contemporânea à época, pressupondo a busca de uma crítica às alienações geradas pela lógica do capital e do militarismo a fim de superá-las e colocar as necessidades humanas como essência das relações sociais. Mas, pelo contrário, as práticas psicológicas humanistas pesquisadas acabavam por harmonizar o indivíduo aos moldes da época, propondo-se a selecionar, adaptar, controlar e predizer o comportamento com a finalidade de impactar o aumento da produtividade.

$\mathrm{O}$ desafio que se coloca às práticas psicológicas orientandas pelas teorias humanistas é o de manter-se, talvez, atreladas aos seus propósitos iniciais, quais sejam o de compreender o homem em sua articulação com o mundo no qual vive e constituído por todas as dimensões culturais de seu tempo. Que desta compreensão derivem ações que promovam a autonomia do indivíduo, tornando-o partícipe da construção de sua história e de sua cultura.

\section{Referências}

Amatuzzi, M. M. (2009). Psicologia fenomenológica: uma aproximação teórica humanista. Estudos de Psicologia, 26(1), 93-100.

Amatuzzi, M. M. (2010). Por uma psicologia humana. Campinas: Editora Alínea.

Coimbra, C. (1995). Guardiães da Ordem. Uma viagem pelas práticas psi no Brasil do "Milagre". São Paulo: Editora Oficina do Autor

Gomes, W.B.; Holanda, A.F. \& Gauer, G. (2004). Primórdios da Psicologia Humanista no Brasil. In Marina Massimi (Org.). História da Psicologia no Brasil no Século XX (p. 87-103). São Paulo: EPU.

Rosa, E. Z. \& Kahhale, E. M. (2002). Psicologia Humanista: uma tentativa de sistematização da denominada terceira força em psicologia. In: Edna Maria Peters Kahhale (Org.). A diversidade da psicologia. Uma construção teórica. São Paulo: Cortez.

Palmer, R. E. (1989). Hermenêutica. Lisboa: Edições 70.

Sacomano, F. \& Faria, N. J. (2014). A psicologia humanista veiculada pela revista "Psicologia Atual", de 1977 a 1986. Memorandum, 27, 161-180.

Saviani, D. (2008). O Legado Educacional do Regime Militar. Caderno Cedes, 28(76), 291-312.

Felipe Sacomano - Graduando em Psicologia na Pontifícia Universidade Católica de Campinas. Email: felipesacomano@gmail.com

Nilton Júlio de Faria - Coordenador do SatoriGT - Centro de Estudos e Pesquisa em Gestalt-terapia e docente da Pontifícia Universidade Católica de Campinas. Av. John Boyd Dunlop, s/n. Jardim Ipaussurama, CEP: 13.060-904 Campinas - SP. Email: njfaria@puc-campinas.edu.br

Yuri Alexandre Ferrete - Graduando em Psicologia na Pontifícia Universidade Católica de Campinas. Email: yuriferrete@yahoo.com.br

Recebido em 10.08.2015 Primeira Decisão Editoria em 21.01.2016 Aceito em 07.04.2016 